\title{
Call for Papers: 1987 MRS Spring Meeting
}

The 1987 Spring Meeting of the Materials Research Society will include 12 topical symposia, an equipment exhibit, a job placement center, and a short course program of approximately 20 courses. MRS extends a broad invitation to materials scientists and engineers to participate in all aspects of the meeting.

The symposia in the 1987 Spring Meeting will share a common goal of discussing new materials development, new characterization methods, or new process technology. Each symposium will provide a forum for exchange of ideas at the forefront of research by experts in the field, and topics will be treated at a sophisticated level in an interdisciplinary way so that all possible physical, chemical, and engineering insights can be considered. The content and timing of sessions of each symposium will be coordinated to minimize concurrency of presentations in areas of common interest.

Papers which will contribute to the state of knowledge in a given area are solicited for all symposium topics. For additional information on a specific symposium, contact the symposium organizers listed at the end of the description for each symposium.

Abstracts are to be submitted to the organizers of the individual symposia. The deadline for abstracts to be in the hands of the symposium chairs is November $7,1986$.

For general information on the technical program for the meeting, contact any of the Program Chairs for the meeting:

R. R. Chianelli

Exxon Research and Engineering Company Clinton Township, Route 22 East

Annandale, NJ 08801

(201) $730-2563$

Graham K. Hubler

Naval Research Laboratory

Code 4671

Washington, DC 20375-5000

(202) 767-4800

Gregory L. Olson

Hughes Research Laboratories

3011 Malibu Canyon Road

Malibu, CA 90265

(213) 317-5457

\section{Symposium A}

\section{Heteroepitaxy on Silicon Technology}

This symposium is the sequel to the very successful one devoted to the same topic at the 1986 Spring MRS Meeting. This series of symposia provides the only forum for discussing the materials and device issues involved in heteroepitaxy on $S i$ in a focused and thorough manner. The successful development of heteroepitaxy on Si would have far-reaching technological applications, ranging from optical communication, to high-speed and novel integrated circuits to solar cells. Impressive progress has recently occurred in the grow th and characterization of material systems which were, until recently, thought to be incompatible. Exciting results have been obtained in devices and circuits fabricated with these new composite materials. This symposium will provide a forum for presenting these results and charting future directions.

Papers are solicited in the following areas:

- Fundamentals of heteroepitaxial growth on $\mathrm{Si}$

- Heteroepitaxy on Si for integrated circuit and optoelectronic applications

- Novel devices and circuits using heteroepitaxy on $\mathrm{Si}$

- GaAs and other III-V compounds on Si

- II-VI compounds on Si

- Heteroepitaxial approaches to three-

dimensional integration on $\mathrm{Si}$

- Superlattice growth on Si

- Epitaxial insulators and metals (including

silicides) on $\mathrm{Si}$

- Group IV heteroepitaxy

Symposium Chairs:

John C.C. Fan

Kopin Corporation

695 Standish Blvd.

Standish Industrial Park

Taunton, MA 02780

(617) 824-6696

Julia M. Phillips

AT\&T Bell Laboratories

Room 1E-43I

600 Mountain Avenue

Murray Hill, NJ 07974

(201) 582-4428

B.-Y. Tsaur

MIT Lincoln Laboratory

244 Wood St

Lexington, MA 02173

(617) 863-5500, extension 7838

\section{Symposium B \\ Rapid Thermal Processing of Electronic Materials}

Rapid thermal processing (RTP) has emerged as an important technique for thin-film modification and growth and for processing high-performance Si ICs and III-V devices. This symposium will highlight the many recent developments in this constantly expanding field. The symposium is the second MRS symposium devoted exclusively to the rapid heating and cooling of electronic materials. Emphasis will be on fundamental material studies and on applications of practical interest to both the Si and GaAs semiconductor industry.
Contributed papers are solicited in the following areas:

- RTP for implantation annealing, dopant activation and diffusion

- Defects and microstructure in RTP materials

- RTP of silicides and metals

- Dielectrics, rapid thermal oxidation, rapid thermal nitridation

- Rapid thermal processing of devices and circuits

- Applications of RTP to compound semiconductors

- Recent developments in RTP equipment - New applications of RTP

Symposium Chairs:

Syd R. Wilson

SRDL, Motorola Inc.

5005 E. McDowell Rd.

Phoenix, AZ 85008

(602) 244-4637

D. Eirug Davies

EOARD

233-231 Old Marylebone Rd.

London NW1 5TH, U.K.

01-409-4437

Ron Powell

Varian Associates

MS K-403

611 Hansen Way

Palo Alto, CA 94304

(415) 424-5078

\section{Symposium C \\ Materials Modification and Growth Using Ion Beams}

The use of ion beams both during and after materials growth is receiving increased attention due to the availability of high-current ion implanters and more sophisticated lower energy ion beam sources. This symposium is intended to bring together investigators of low, intermediate, and high energy ion-activated processes for materials modification. We anticipate that it will be a forum for presenting innovative ongoing work on both fundamental and applied issues.

Planned Sessions:

- Ion-Solid Interactions: fundamental studies of the processes involved in ion bombardment, both during and after growth. Semiconductors, dielectrics, and metals will be considered

- Ion Beam Deposition: production of films directly from an ionized vapor or cluster course. Modification of film properties and methods of production will be covered.

- Beam-Induced Mixing and Diffusion: disordering of multilayered systems for localized bandgap engineering and metas- 
table phase formation. The emphasis will be on semiconductor systems, but related contributions will be welcomed.

- High-Dose Ion Implantation: specifically for studying formation of buried layers of oxide, nitride, etc. Methods of production and electrical characterization of surface layers will be discussed.

- Tribological Coatings: ion beam techniques for the fabrication of nitride, carbide, etc. coatings, and properties of these coatings.

- Optical Coatings: ion-beam-assisted deposition and other techniques for producing improved transparent and reflective coatings.

Symposium Chairs:

Ursula Gibson

Optical Sciences Center

Room 724

University of Arizona

Tucson, AZ 85721

(602) 621-2539

Peter P. Pronko

Materials Research Division, Code 40

Universal Energy Systems

4401 Dayton-Xenia Rd.

Dayton, $\mathrm{OH} 45432$

(513) 426-6900, extension 113

Alice E. White

AT\&T Bell Laboratories

Room 1E-433600

Mountain Avenue

Murray Hill, N] 07974

(201) 582-2506

\section{Symposium D}

\section{Initial Stages of Epitaxial Growth}

Epitaxial growth is crucially important to the semiconductor industry, and is central to the development of new semiconductor devices and to extending the frontiers of solid state physics. The fundamental mechanisms of epitaxial growth, however, remain poorly understood. In this symposium, it is planned to examine and advance state-of-the-art understanding of the initial stages of epitaxial growth by combining knowledge derived from classical approaches (e.g., thermodynamical and nucleation studies) with up-to-theminute results from emerging fields such as ultrahigh precision crystal growth techniques, molecular dynamics simulations, and in situcharacterization techniques. This symposium will thus bring together scientists concentrating on understanding the fundamentals of epitaxial growth, rather than technological properties of epitaxial structures.

Areas to be addressed in the symposium include, but are not limited to:

- Nucleation phenomena in epitaxial crystal growth techniques (MBE, LPE, MOCVD, etc.)
- Experimental characterization and modeling of epitaxial growth, particularly by in situ techniques (TEM, RBS, AES, RHEED, etc.)

- Theoretical studies of nucleation, condensation, and surface migration.

- Computer simulations of epitaxial growth.

- Understanding of processes/forces governing epitaxy (e.g. lattice misfit, chemical bonding, surface reconstruction, graphoepitaxy).

Symposium Chairs:

Robert Hull

HP Laboratories

3500 Deer Creek Road

Palo Alto, CA 94304

(415) 857-6227

J. Murray Gibson

AT\&T Bell Laboratories

600 Mountain Avenue

Murray Hill, NJ 07974

(201) 582-5952

David A. Smith

IBM T.J. Watson Research Center

Yorktown Heights, NY 10598

(914) 945-2512

\section{Symposium E Amorphous Silicon Semiconductors- Pure and Hydrogenated}

This symposium will be concerned with materials issues related to applications to a morphous semiconductors, including amorphous silicon-based alloys and chalcogenide glasses. The specific issues involved include structure, electronic and optical properties, defects, interfaces, contacts, heterostructures, nonequilibrium behavior, and stability. Applications include solar cells, electrophotography, switching, electronic and optical memories, image sensors, scanners, thin-film transistors, vidicons, large-area displays, portable computers, and new types of devices. The symposium will focus on the electronic density of states and its relationship to technological figures of merit for each application, fundamental and materials limitations, yield, reproducibility, reliability, and stability.

Papers are solicited for, but not limited to, the following areas:

- Structure

- Optical properties

- Electronic properties

- Defects

- Contacts

- Interfaces

- Heterostructures

- Stability

- Nonequilibrium properties

- Image sensors

- Transient behavior

- Alloys

- Solar cells
- Electrophotography

- Switching

- Electronic memories

- Optical memories

- Computers

- Large-area displays

- Vidicons

- Scanners

- Novel devices

Sympositum Chairs:

D. Adler

MIT 13-3050

77 Massachusetts Avenue

Cambridge, MA 02139

(617) 253-6868

Y. Hamakawa

Osaka University

1-1 Machikaneyama

Toyonaka

Osaka 560, Japan

A. Madan

Glasstech Solar, Inc.

$1244 \mathrm{I} \mathrm{W.} \mathrm{49th} \mathrm{Avenue}$

Wheat Ridge, CO 80033

(303) 425-6600

M. Thompson

Xerox PARC

3333 Coyote Hill Road

Palo Alto, CA 94304

(415) 494-4561

\section{Permanent Magnet Materials}

Research on rare earth intermetallic materials has received considerable recent impetus, in part as a consequence of the development of powerful permanent magnets prepared from neodymium-iron-boron alloys. New crystal structures and magnetic configurations have been identified and novel preparation methods leading to a spectrum of microstructures have been employed. The symposium will examine several aspects of this vigorous and expanding area with the intent of providing a coherent picture of its current status as well as its probable future course. Major topics of the symposium will include preparation techniques, intrinsic properties, applications, and future directions.

Papers are solicited in the following areas:

- Materials synthesis-e.g., powder metallurgy, rapid solidifiction

- Fundamental properties-magnetization, crystal fields, substitutional effects, etc.

- Applications-motors, NMR imaging

Abstracts of contributed papers should be sent to Dr. J.F. Herbst at the address below.

Continued 
Symposium Chairs:

S. G. Sankar

Materials Research Laboratory

The Pennsylvania State University

University Park, PA 16802

(814) 865-1645

J. F. Herbst

Physics Department

General Motors Research Laboratories

Warren, Ml 48090-9055

(313) $575-3382$

N. C. Koon

Naval Research Laboratory

Washington, DC 20375

(202) 767-2360

\section{Symposium G}

\section{Science and Fabrication of Small Clusters}

The transition from molecular to bulklike properties of clusters is in the range from a few atoms to a few hundred constituent atoms. This is the regime where domination by surface atoms is gradually supplanted by the evolution of bulk-like interior atoms. The full transition to include long-range order and the ability to stabilize most surface states requires even larger cluster sizes involving thousands of atoms. The small cluster regime is the primary focus of this symposium because it is especially important from both a fundamental scientific perspective and potential technological implications.

Special emphasis will be on size-sensitive properties of a novel state of mattermolecular surfaces. This area lies at the confluence of interdisciplinary science involving chemistry, physics, and materials science. The purpose of this symposium is to expose to the materials science community significant new findings in sizesensitive behavior, structural, electronic, magnetic, optical, and chemical properties of cluster materials-metals, compounds, alloys, and their respective ions, as a function of constituent atoms, as well as recent advances in experimental and theoretical approaches to prepare and characterize materials in this size range. Techniques to produce, stabilize, and characterize single size supported materials a re of special interest.

\section{Symposium Chairs:}

\section{Andrew Kaldor}

Exxon Research and Engineering Company Route 22E

Annaindale, NJ 08801

(201) 730-3004

\section{S. Riley}

Argonne National Laboratory

Building 200

Argonne, IL 60439

(312) $972-6793$

\section{Symposium H \\ Synthesis and Properties of Novel Cata- lysts: Carbides, Nitrides, Borides, and Silicides}

This symposium is devoted to fundamental aspects of the synthesis and characterization of novel catalytic materials, including carbides, nitrides, borides, and silicides. It provides a forum for discussion of synthetic routes to high-surface-area refractory materials and their potential use as catalysts. Particular attention will be given to theoretical and experimental studies of the bulk and surface properties of these materials.

Papers are solicited in the following areas:

- Synthetic routes to high-surface-area refractory materials

- Defect structure and electronic properties

- Bulk characterization, including crystallography and NMR

- Surface studies in ultrahigh vacuum

- Catalytic properties of refractory materials

- Metal-support interactions on carboncontaining supports

Symposium Chairs:

Angelica M. Stacy

Department of Chemistry

University of California

Berkeley, CA 94720

(415) 642-3450

James N. Michaels

Department of Chemical Engineering

University of California

Berkeley, CA 94720

(415) 642-2408

\section{Symposium I}

\section{Novel Refractory Semiconductors}

This symposium will highlight recent developments in the study of refractory semiconductors. Such materials include, but are not restricted to, icosahedral borides, silicon carbide, diamond, and rareearth chalcogens. The symposium will consider fundamental problems as well as device and applications issues.

Papers are solicited in the following areas of refractory semiconductor research:

- Synthesis and doping

- Structure

- Material characterization

- Electronic properties

- Magnetic properties

- Thermal properties

- Applications and devices

Sympositum Chairs:

Terry Aselage

Division 1842

Sandia National Laboratories

Albuquerque, NM 87185

(505) 844-0949
David Emin

Division 1151

Sandia National Laboratories

Albuquerque, NM 87185

(505) 844-3431

Charles Wood

MS 277-212

Jet Propulsion Laboratories

Pasadena, CA 91109

(818) 354-4036

\section{Symposium J \\ Geological Materials: Silicate Melts and Glasses}

Major advances in the study of silicate melts and glasses have recently emerged from several disciplines, including earth sciences, condensed-matter physics, and materials science. The purpose of this symposium is to bring together researchers from widely dispersed fields to compare the latest results on the structure, $d y$ namics, and physical properties of these materials.

The following are among the topics to be discussed:

- Structure and statistical mechanics of melts and glasses: relationship to physical properties

- Anelastic moduli, high-pressure equations of state, and transport properties of melts

- Thermodynamics of melts and melt interfaces

- Melting and glass formation to ultrahigh (megabar) pressures

- Glass dynamics: low-temperature anomalies, pressure-quenching, and crystalline analogies

Symposium Chairs:

Raymond Jeanloz

Department of Geology and Geophysics

University of California

Berkeley, CA 94720

(415) $642-2639$ or $642-3993$

Gordon E. Brown

Department of Geology and Center for Materials Research

Stanford University

Stanford, CA 94305

(415) 723-3518

Hubert E. King, Jr.

Exxon Research and Engineering Company Clinton Township

Annandale, NJ 08801

(201) $730-2885$

\section{Symposium $\mathbf{K}$ \\ Plasma Processing and Synthesis of Materials}

Materials processing by the use of plasmas is a rapidly growing field. The quest for materials having novel microstructures, synthesizing new materials, the manufacture of gradient materials, and extractingl 
processing metals and ceramics are all being achieved by the use of plasma processing. The purpose of this symposium is to bring together scientists and engineers active in the plasma processing of materials to discuss both fundamental and technology related issues. Contributed papers are invited in the following areas:

- Modeling (to include both thermal and low-pressure plasmas)

- Diagnostics

- Plasma synthesis

- Surface modification, including coatings

- Melting and extractive

- Low-pressure plasma, PECVD, and plasma etching

Symposium Chairs:

Diran Apelian

Professor and Head

Materials Engineering

Drexel University

Philadelphia, PA 19104

(215) 895-2322

Julian Szekely

Professor

Materials Science and Engineering

MIT

Cambridge, MA 02139

(617) 253-3236

\section{Symposium L}

\section{Materials for Aerospace Applications}

The Materials Research Society and its Southern California Section are organizing this symposium to be held during the MRS Annual Spring Meeting in Anaheim, CA. This is the first such symposium to be organized by MRS in recognition of the materials-related issues specifically and critically important to applications in the aerospace and space industry. As such, the objectives of the symposium are: (1) to promote greater awareness among materials scientists of such practical issues, and of related research opportunities and challenges; (2) to enhance interaction between materials research and materials application oriented communities, as well as cross-fertilization of ideas.

The topics/areas to be emphasized are:

- Metal matrix composites

- Ceramics for high-temperature applications

- Organic matrix composites

- Materials response in low orbits to oxygen-radical interactions

Symposinm Chairs:

A. Madhukar

Department of Materials Science

University of Southern California

Los Angeles, CA 90089-0241

(213) 743-6929

L. Leger

NASA Johnson Space Center

Mail Stop ES-5

Houston, TX 77058

(713) $483-2059$

\section{MRS}

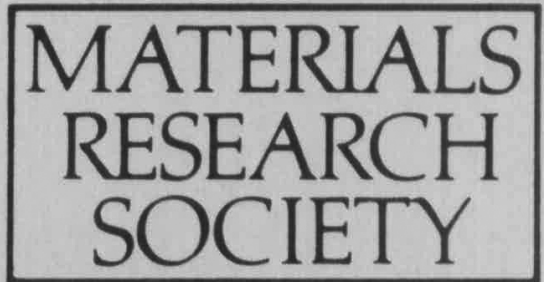

\section{Candidates Sought for Graduate Student Awards at 1987 Spring Meeting}

The Materials Research Society announces the availability of several awards for graduate students conducting research on a topic to be addressed in a symposium at the 1987 Spring Meeting. Each award will consist of a cash grant of $\$ 250$, to be presented at ceremonies during the meeting, and a waiver of the meeting registration fee.

Criteria for selection are:

1. Graduate standing in a recognized academic program in materials science, metallurgy, ceramics, or polymers; physics or chemistry; geology or mineral science; electrical, civil, mechanical, mining, or nuclear engineering; or other materials-related field.

2. Participation in the 1987 Spring Meeting by being an author or coauthor of a paper presented in one of the symposia.

3. Outstanding performance in the conduct of the research project and promise for future substantial achievement in materials research as judged by the faculty advisor.

4. Significant and timely research results as judged by the chair of the appropriate symposium.

Application materials required are:

1. Application form obtainable from MRS Headquarters.

2. Abstract of paper to be presented at the meeting

3. Letter of support from research supervisor.

Deadline for completed application is February 1, 1987. Awards will be announced March 1, 1987. Obtain application form and submit completed application to:
John B. Ballance
Executive Director
Materials Research Society
9800 McKnight Road, Suite 327
Pittsburgh, PA 15237
Telephone: (412) 367-3003 